\title{
User Innovation Decision-Making Mechanism Based on Industry Heterogeneity-Double Case Study of Huawei and Haier
}

\author{
Jingyi Yan ${ }^{1, a}$ \\ ${ }^{1}$ Nanhu campus of Wuhan university of technology, Wuhan city, \\ Hubei province, the People's Republic of China \\ a1719296145@qq.com \\ *Jingyi Yan
}

Keywords: User engagement innovation, Case studies, Industry heterogeneity

\begin{abstract}
With the comprehensive popularization of the Internet, the arrival of the era of experience economy and the increasingly intensified market competition, user participation has become an important factor that cannot be ignored when enterprises develop new products or add new services. Huawei and Haier are both benchmark enterprises in the field of innovation practice of Chinese enterprises. Therefore, this paper selects Huawei and Haier as double cases to study the mechanism and difference of users' participation in collaborative innovation of the two companies, and finds that the different collaborative innovation methods of the two companies are related to the different industries they are in. This study can provide some references for Chinese enterprises to take the road of "innovation-driven development".
\end{abstract}

\section{Introduction}

With the rapid development of economy, many enterprises in China have gradually start internationalization. However, because of relying too much on technology import, they are less creative and lack core competence, and then was forced to withdraw from the market. In view of this situation, the executive meeting of the State Council in July 2017 pointed out that we should further implement the strategy of innovation-driven development, further foster an integrated, coordinated and shared environment for mass entrepreneurship and innovation, and promote the in-depth development of mass entrepreneurship and innovation.

The advent of the era of Internet technology and economy has accelerated the update of technology and put forward higher requirements on the innovation ability of enterprises. Innovation activities cannot be sustained only by enterprises themselves. In addition, the personalized needs of consumers are also generated, standardized products and services can no longer meet the needs of users, and integrated solutions are the favorite of today's users, which cannot be completed by an enterprise with only professional knowledge and capabilities in some fields. Therefore, the role of user participation in collaborative innovation is increasingly prominent. Both Huawei and Haier can be attach great importance to user participation that can be called model, but they have different characteristics. Therefore, this paper selects Huawei and Haier as case studies to study the decision-making mechanism of user collaborative innovation in different industries.

\section{The development history of Haier group and Huawei}

\subsection{The development history of Haier group}

Haier group was founded in 1984, after 30 years of development, has grown to become the first brand in China's home appliance industry. From 1992 to 1998, Haier successfully implemented the diversification strategy, and from 1998 to 2005, Haier fully implemented the internationalization strategy. Beginning in 2006, Haier has entered the period of globalization strategy. Since 2012, in the era of digital economy, Haier started the process of the networking, break original traditional enterprise architecture and committed to build platform enterprise, to take advantage of the global 
resources effectively, further expand the international market. In 2013, the "maker movement" was launched in Haier, encouraging employees to create small and micro enterprises in Haier by using enterprise resource platform. By the end of 2016, Haier had more than 200 micro businesses and more than 1,160 projects. At the same time, more than 100 micro businesses had an annual revenue of more than 100 million yuan. 22 micro businesses had been introduced into venture capital, and 12 had a valuation of more than 100 million yuan. Since 2013, Haier has obtained nearly 10,000 invention patents, 3988 practical new models and 2197 overseas patents. In July 2018, "wisdom family system framework and the general requirements" and "the general requirements for networking and interoperability specification" adopted two international standard review institute of electrical and electronics engineers and project successfully, marks Haier's innovative practice and innovation ability in intelligent family won the international standards organization recognized authority.

Take Raytheon, the first small and micro startup company founded after Haier group implemented the network strategy as an example. Based on the core product of game notebook, Raytheon launched game desktop and game peripheral products, and actively carried out product design, research and development and sales. The existing research and development content mainly involves computer application layer technology. On the basis of paying attention to user needs, Raytheon has gained insight into user needs ahead of competitors, focused on product development and production, and transformed user demands into products with the fastest speed, so as to obtain benefits through continuous technological innovation.

\subsection{Development history of Huawei}

Since its establishment in1987, Huawei has invested a huge amount of money in scientific research, and it is mandatory to allocate $10 \%$ of sales to scientific research every year. Huawei invested 59.6 billion yuan in R\&D of new technologies, new products and wireless communication in 2015, accounting for $15 \%$ of sales revenue. In the past decade, Huawei invested 240 billion yuan in R\&D. Only more than 20 years, Huawei grow from a little-known Chinese enterprises become the world's largest telecommunications equipment manufacturers. In 2015, as the world's biggest wireless communication equipment manufacturers, in 2018 at the 83th in the world 500 strong enterprises, done in the world's most valuable brand rankings ranked 70, became the world's leading ICT infrastructure, the intelligent terminal and solution provider. By the end of 2018, Huawei had obtained 87,805 patents, applied for 43,371 Chinese patents and 44,434 foreign patents, among which more than $90 \%$ were invention patents. He has won the state science and technology award for 10 consecutive years, and has mastered such world-leading technologies as 5G communication technology, cloud computing, big data, artificial intelligence technology, graphene technology and network security technology. In recent years, especially in 2018, Huawei's development of 5G network has made it difficult for many enterprises to compete with it, and the battle between Huawei and Qualcomm for $5 \mathrm{G}$ standards has become a battle attracting worldwide attention.

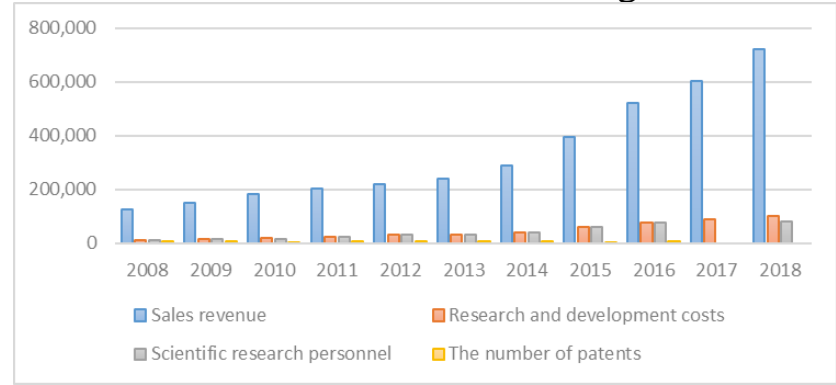

Fig..1Research and development output data of Huawei from 2008 to 2018

\section{Collaborative innovation decision-making mechanism}

This paper divides the user participation collaborative innovation into three stages: stimulation, conduction and adoption. The stimulation of user innovation is the starting point of user participation in innovation, that is, through a certain incentive mechanism, to stimulate users' initiative to create 
products in demand. Inviting users to participate in the initial stage of product innovation can avoid the loss caused by large-scale modification, or even redesign and development after problems are found after product testing and use. Transmission process refers to the process in which users' ideas are transmitted to enterprises. The efficiency and accuracy of transmission affect whether users' ideas can be further implemented. Adoption refers to the process enterprises adopt and form product innovation plans after evaluating and analyzing users' ideas through big data analysis or other means.

\subsection{User participation in the innovation process of Haier group}

\subsubsection{Process of stimulation}

Haier has developed user service applications, such as "Haier's best home" application, which can support user's module customization and exclusive customization. Private custom service experience effectively encourage users to participate in the design of the product research and development. At the same time, the BBS, the user community called "Haixinghui", make the user needs to convey more conveniently. In the community, users can not only publish product defects, personalized needs and improvement ideas, but also see other users' Suggestions. Moreover, Haier also arranged professional engineers to interact with users and discuss solutions, which improved users' creativity. HOPE platform, which was officially launched in 2013, as the largest open innovation platform in China, integrates users, suppliers and other relevant groups together, enabling users' innovation to be directly spread to relevant operators and further arousing users' enthusiasm to participate in innovation.

\subsubsection{Process of conduction}

Haier has more than 30,000 offline stores all over the country, which can timely receive the personalized needs of users. In addition, the user community built by Haier has attracted more than 100,000 registered users, including experts in related fields and researchers in universities and institutes. The technical requirements published here can be easily spread. HOPE platform brings together users, suppliers, internal employees or other innovative entities to realize transmission more efficiently and accurately.

\subsubsection{Process of adoption}

The establishment of the data platform of SCRM social customer management system enables Haier to acquire data by virtue of SCRM, accurately obtain the existing and potential needs of users for products through big data analysis, and effectively solve the priority problem in the process of user innovation and adoption. Haier's platform strategy also supports zero-distance contact between employees and users, which increases the opportunity of combination of technical support and innovation and effectively promotes the adoption of innovative knowledge.

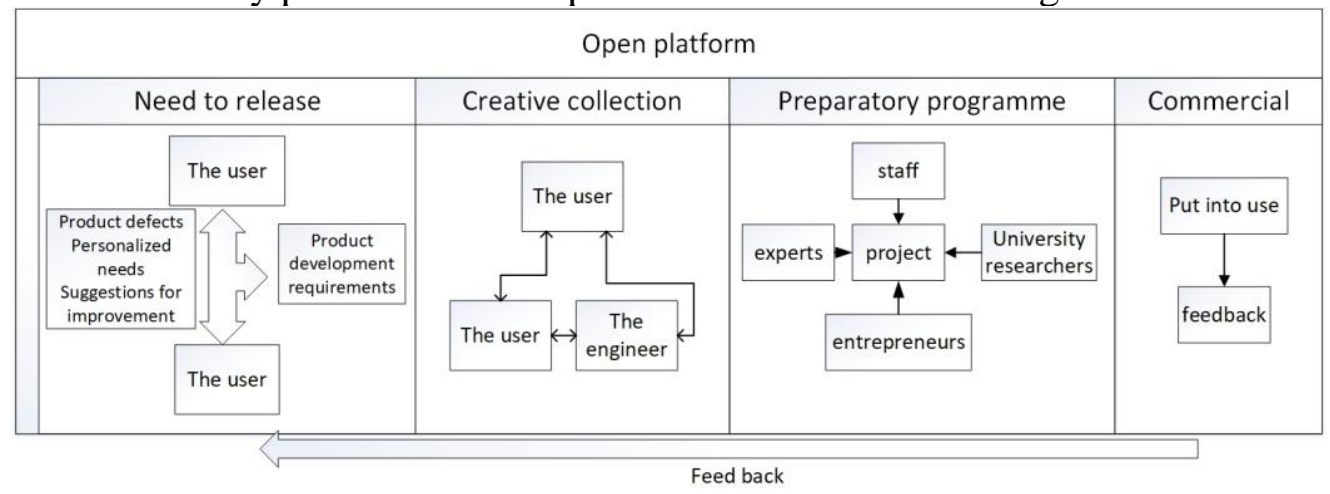

Fig.2Flow chart of Haier collaborative innovation mechanism

\subsection{Mechanism for Huawei users to participate in innovation}

\subsubsection{User participation in the stimulation of innovation}

Aiming at the stimulation of individual consumers such as mobile phone buyers, Huawei has established the "Pollen club" online business platform for fans to exchange activities and explore users' ideas. In addition, Huawei also set up an offline entity fan club around the university to attract college students to participate in innovation by carrying out original emotion UI design, ID design, 
bate test and other activities. Up to 2014, Huawei has set up "Pollen club" in more than 60 universities in China. Relying on the natural advantages of universities, Huawei has acquired a lot of innovative knowledge and used the results submitted by users selectively for the development and innovation of enterprises. Huawei has established long-term technical cooperation relations with Tsinghua university, Beijing university, University of Science and Technology of China and other universities of posts and telecommunications. Through the establishment of a joint laboratory or the purchase of technology, Huawei has conducted cooperation in technology innovation, such as narrowband CDMA technology and smart network technology.

For large user of innovation, such as enterprise, Huawei is adopted to establish the interests of the community. Huawei and customer is not only a simple price game relationship between both parties, they can also share certain profit. Under the drive of interests, the enthusiasm of the customers to participate in collaborative innovation is greatly inspired, designed and developed by supplier or the user participation, provide value solutions, achieve win-win situation. Huawei and MOTOROLA's cooperation, for example, in 2002, the two sides began OEM strategic cooperation, Huawei through MOTOROLA channel not only exports more products, also promoted its own technical level through the research and development cooperation, in addition, Huawei with telefonica, international leading carriers such as telecom italia, set up multiple joint innovation center, carry out joint innovation with customers, common innovation.

\subsection{2 process of conduction}

According to the geographical distribution characteristics of the market, Huawei now has more than 100 permanent offices or representative offices stationed abroad, which are distributed all over the world. With direct contact with users, Huawei can give in-depth and timely feedback on customer innovation and customer demand."Pollen club" online platform effectively spreads the needs of users and innovative users to enterprises, while Huawei has set up more than 40 capacity centers and more than 30 sharing centers around the world relying on its geographical advantages, and established 31 joint innovation centers and 16 research and development centers with customers, creating a transmission network all over the world. Chicago, for example, focuses on next-generation networking, chip technology and software; the Indian institute is responsible for software development; and Moscow focuses on basic algorithms. Huawei established the European institute in 2018 and invested heavily in the research and development and innovation of cutting-edge 5G technology, with remarkable results. Huawei holds regular meetings according to customer needs in the innovation network, conveys product requirements, and seeks cooperation objects with the ability and common goals to achieve collaborative innovation. For example, relying on the advantages of a large number of mathematicians and engineers in Russia, Huawei's Russian research institute has realized the innovation of mathematical algorithm, developed the creative single RAN technology on this basis, and realized the integration of $2 \mathrm{G}, 3 \mathrm{G}$ and $4 \mathrm{G}$ networks, which has laid a good foundation for Huawei to successfully enter the European market.

\subsubsection{Process of adoption}

Huawei has set up a special public opinion analysis department to collect innovative knowledge and user needs. Huawei has a clear positioning and direction for its products, and selects the preferred innovative knowledge or customer needs through its own understanding, so as to achieve the purpose of scheduling and organizing resources and seizing market opportunities.

\section{Differences between Huawei and Haier in the decision-making mechanism of user participation in collaborative innovation}

In the process of user participation in collaborative innovation, Haier, complete the open platform, let all participants involved in all links, user products from passive recipients into product research and development, manufacture, sale and use of the whole process of the participants, and is involved in at the same time, the process between nodes is no longer linked together, but the mutual fusion, at the same time relationship. As long as the user has an idea, no matter it is about any link of the idea, can put forward at any time, effectively improve the efficiency of the organization operation.

In the innovation process, Huawei experienced a relatively "traditional" cycle: innovate, integrate 
and release new products -- collect user Suggestions and innovative knowledge -- analyze and select some innovative knowledge and user opinions to adopt first -- integrate, innovate and release new products. In Huawei's own product has clear positioning and the direction of fully open but not to rely too much on the user innovation, through the analysis of their own choice feasible innovation knowledge, and through their own strong users to participate in the innovation network "distribution" need of cooperation, the collaborative research task, by the distribution of global dozens of joint contact related professionals in the field of innovation center, achieve users to participate in innovation, then make the product can meet the needs of customers can bring a surprise to customer again.

Huawei always holds the main direction of innovation in the process of users' participation in innovation and pays attention to the distribution and ownership of property rights. Haier, on the other hand, gave the right to choose to the free collision of innovative knowledge and existing technology, and let the market test the results of innovation.

\section{Analysis of the difference of user participation in collaborative innovation decision-making mechanism based on industry heterogeneity}

Haier realizes user innovation by building a sharing platform. Compared with Huawei's huge investment in global innovation network construction, Haier's user participation and collaborative innovation are more "economical". Huawei and Haier have different mechanisms of user participation in innovation, for the following reasons.

\subsection{Home appliance industry and communication industry face different innovation requirements.}

No matter in which industry, market competition, in the final analysis is product competition. In the communication industry where Huawei is located, products come from technology, and the profits of followers and imitators are easy to be compressed. However, technological innovators can lead the market demand with the help of original technology, and often obtain excess profits and invest the profits in the next round of research and development, forming a virtuous circle. The originator can even register a patent to control the entry of the technology into the market, which risks the followers and imitators being completely squeezed out of the market. So Huawei always innovation as enterprise development is the most important support, integration is the important strategic choice for Huawei in this background and the way of organization, therefore, Huawei focus on innovative technology, control other companies do not research and development of the technology, and to offer valuable technology and extend the functionality, mastering the technology development in the future.

Haier's home appliance industry, innovation, under the age of the Internet has had a profound change, especially the advent of the era of smart home, make home appliance industry greatly increase to the requirement of knowledge and technology foundation, electrical appliances product innovation is not only based on the traditional electrical and mechanical technology, and increasingly with basic science, in the field of electronic and information engineering, and other industry technology fusion penetration. The complexity of knowledge and technology, and the cross-border demand for innovation of Haier are far beyond Huawei. It is unrealistic for Haier to build an integrated enterprise like Huawei. Building a sharing platform to realize innovation is of great significance for Haier to maintain its competitiveness in the rapidly changing Internet era.

\subsection{The R\&D investment of household appliance industry and communication industry has different profitability for enterprises.}

The research and development investment of household appliances industry has a certain lag in the profitability of enterprises, while the research and development investment of communication industry has no lag in the profitability of enterprises. Data show that home appliances industry profit lag can usually be about three years. The main reasons are as follows.

1. For the household appliance industry, research and development itself has a long cycle. It takes 
a long time to develop results, apply new technologies to products, produce products for sale, and products are recognized by consumers to make profits. However, the communication industry can achieve rapid investment and cost recovery. For example, the emergence of $4 \mathrm{G}$ technology soon makes the communication industry a new profit growth point.

2. The demand for home appliances is far lower than that of mobile phones. Household appliances belong to durable consumer goods. The appliances purchased by the previous generation of consumers can often last ten to twenty years or even longer. If it were not for the demand of buying a new house or updating products, people would not choose to buy appliances with the same performance. At the same time, the demand of people to home appliance is limited, often one family (3-4 people) just can have the demand that USES a kind of home appliance, make home appliance industry is easy saturated. And Huawei's communications industry, along with the development of the economy, increasing smartphone penetration, almost every cell phone, at the same time compared to home appliances, mobile phone use fixed number of year of only 1 to 3 years, has a much broader market, is also introduced new technology and new products, Huawei audiences than Haier, profitability is also higher. Therefore, Huawei has spared no expense to build an integrated enterprise to master core technologies.

3. People have different requirements on the quality of home appliances and communication equipment. In the household appliance industry, what users need more is durable products, rather than the pursuit of novelty as in the communication industry. Therefore, in addition to R\&D investment, Haier also needs to pay attention to product quality assurance, which means high cost investment in product production process, prompting Haier to seek ways to reduce R\&D cost for user innovation, so as to improve enterprise competitiveness. However, mobile phones and other products are consumables themselves with limited service life. In the process of using communication equipment, users enjoy the leading technology instead of the equipment itself. The enterprise can guarantee that the life safety of users is not threatened in the process of use.

\section{Analysis of the user participation collaborative innovation decision-making mechanism between Huawei and Haier}

Haier's platform construction to a certain extent reduces the cost of research and development and further improves the competitiveness of the enterprise. In addition, the platform provides a wider space for knowledge creation, diversified information here fully interactive, make knowledge innovation has the possibility of a larger, on big data platform, many people think that marginal information and knowledge have the opportunity to associate, seemingly "impossible" knowledge also can form ideas, and constantly developed in this space, eventually create unexpected value. But the establishment of a broad sharing platform, does not mean that can create a competitive advantage for enterprises; The successful sharing platform at the present stage cannot guarantee the sustainable competitive advantage. Nokia's Symbian ecosystem, such as IBM's open computer platform, has not given companies a lasting competitive advantage. In addition, the sharing platform is also faced with the problems of high transaction cost, low effectiveness of division of labor, fuzzy interface, loose cooperation, delayed risk detection and uncertainty. In the complex knowledge community, the grasp of knowledge is the most difficult thing. Naturally, problems of free riding, moral hazard and knowledge ossification inevitably appear, which lead to the increase of transaction cost and the ossification of ecosystem. How to change the technology interaction from passive to active, and how to continuously introduce new subjects to the platform instead of merely continuing existing subjects, is worthy of further exploration by Haier.

Huawei sets up research and development institutions in global talent gathering places, which can not only acquire local leading technologies, but also gain insight into industry opportunities, which is conducive to grasping the direction of innovation. Research and development institutes in different regions focus on different research and development directions, realizing the complementary advantages of enterprises in the global scope. In the process of collaborative innovation, users can not only accelerate the accumulation of their own technologies, but also focus on the research and development of core technologies, which is conducive to the realization of technological 
breakthroughs in core fields. However, due to the integrated construction of Huawei, some innovative knowledge cannot play its maximum value, or it can be directly stopped in the conception stage. It may even turn to other enterprises or self-organized innovation and put it into the market as a new competitor. How to timely capture users' seemingly "useless" innovative knowledge needs further study by Huawei.

\section{Summary}

With the in-depth development of the "Internet plus" economy, new business models such as personalized customization and connected factories have been vigorously promoted. The core of these new models is user innovation. Both Huawei and Haier are benchmark enterprises in the field of user participation in innovation practice of Chinese enterprises. Among them, Haier focuses on building an open platform, advocating resource sharing and encouraging innovation, while Huawei pays attention to extensively absorbing knowledge and strengthening integration construction. The difference between the two is mainly due to the different requirements and profitability of innovation in household appliances and communication industries. Of course, enterprises should have a good degree of openness when carrying out user participation in innovation, so as to not only ensure that the core technology of the enterprise will not be shaken, but also realize the stable and sustained growth of the enterprise in the Internet economy through user participation in innovation.

\section{References}

[1] Shuilian Wang, Yingying Du. Comparative study on the open innovation models of Haier, Lenovo and Xiaomi [J]. Science and technology and industry,2017,17(08):94-98.

[2] Tongtong Zheng. Research on the mechanism and model of user innovation [D]. Wuhan university of technology,2014.

[3] Ling Ding. Research on enterprise technology innovation based on user participation [D]. Southwest university of science and technology,2014.

[4] Jin Lin, Tong Wang. The practice of marketing theory research - in Huawei pollen club, for example [J]. China, 2014 (34): 15 to 17.R

[5] Dandan Zhao. Research on the impact of enterprise R\&D investment on enterprise profitability [D]. China university of geosciences (Beijing),2017. 